\title{
Assessment \& management of sexual problems in women
}

Kevan Wylie

J R Soc Med 2007; 100:547-550

This article is the sixth in a series of articles on sexuality and sexual health.

\section{INTRODUCTION}

Sexual dysfunction in women is, according to many studies, a common experience. The definition of dysfunction may vary widely, and there are concerns about distinguishing sexual concerns, difficulties, disorders and dysfunctions (SCDDD). However, such a differentiation may be useful during the initial assessment.

\section{PREVALENCE}

Prevalence rates for SCDDD of $43 \%$ of women and 33\% of men in the USA (based on a national probability sample of 1749 women and 1410 men) ${ }^{1}$ and $41 \%$ in England ${ }^{2}$ are cited. $53.8 \%$ of women had a minimum of one sexual problem lasting at least one month over a two-year period in the UK. ${ }^{3}$ More than $40 \%$ of female respondents in a national survey of women in heterosexual relationships reported sexual problems, ${ }^{4}$ as did an even higher number in a study in Brazil (49\% of women). ${ }^{5}$ There is an age difference-22\% of women aged 18-27 years and $66 \%$ of women aged $48-57$ years in Turkey; ${ }^{6}$ and $22 \%$ in the 40 44 age group versus $66 \%$ in the 60-64 age group in Santiago, Chile. ${ }^{7}$ Lower educational levels affect prevalence rates. ${ }^{1,8}$ The risk of female sexual dysfunction (FSD) halved in graduate women compared to those who did not finish studies; ${ }^{1}$ while completing more than 12 years of education reduced risk by $36 \%{ }^{8}$ There may be low prevalence of FSD (e.g. $27 \%$ in Morocco) $;{ }^{9}$ however, many question these rates-Moynihan most vociferously. ${ }^{10}$

A review of published prevalence studies listing categories of desire, arousal, orgasm and pain, with a response rate greater than $50 \%$ or sample size greater than 100 , found that 11 of 1248 studies met inclusion criteria. The results of these studies revealed that 64\% (16-75\%) experienced desire difficulty; 35\% experienced orgasm difficulty; $31 \%$ experienced arousal difficulty; 26\% experienced sexual pain; and 62-89\% had problems persisting for at least several months, of which 25-28\%

Consultant in Sexual Medicine, Sheffield

Email: k.r.wylie@sheffield.ac.uk persisted for six months or more. ${ }^{11}$ Mercer et al. ${ }^{3}$ reported that many problems only lasted for a few months.

How do these women explain their problems? The most common reason cited is conflict in the relationship — such as loss of intimacy, intimidating atmosphere or poor communication (72.3\%). Other reasons included poor knowledge of their bodies and sexually sensitive areas (49.3\%); partner sexual dysfunction $(82 \%)$; poor partner performance and technique (87\%); personal psychopathological problems (66.4\%); and history of trauma, including genital, obstetrics, etc. $(42.6 \%) .^{8}$

\section{GETTING THE PATIENT AND THE PHYSICIAN TO BROACH THE SUBJECT}

Sexual fulfilment is an important part of sexual health. Sexual behaviours significantly associated with reporting sexual function problems included competence at first sex, paying for sex in the past five years, and the number of occasions of sex and / or masturbation in the past four weeks. ${ }^{12}$ It is therefore unsurprising that patients are more content to turn to their physician for help. $42 \%$ of women with sexual complaints sought help from their gynaecologist, and 54\% of those who did not seek help stated they would like to. ${ }^{13}$ Sexual health concerns were found in $98.8 \%$ of 1480 women seeking routine gynaecological care. ${ }^{14}$

Some circumstances may make it more difficult to talk to physicians. Only $15 \%$ of women with a sexual problem during the postnatal period reported discussing it with a health-care professional. ${ }^{15}$ This is important, as childbirth appears to have a lasting impact on sexual function well beyond the postpartum period, due more to psychological factors than to physical ones. ${ }^{16}$

One major disorder, Hypoactive Sexual Desire Disorder (HSDD), is associated with low sexual desire and distress. Older women are more likely to experience HSDD than are younger women are, but younger women are more likely to experience distress because of it. ${ }^{17}$

Training physicians in communication skills seems to be fundamental for sexual history-taking and the management of sexual problems, as it improves their level of comfort in dealing with sexual issues. A good undergraduate curriculum may be an essential starting point. ${ }^{18}$ Other beneficial options include attending sexual medicine 
courses, psychosocial orientation and looking at physicians' personal sexual attitudes. ${ }^{19}$

Characteristics identified by physicians as causing discomfort were interviewing opposite gender patients, patients aged less than 18 or more than 65 years, patients whose academic achievement is below college level, and patients who are divorced or single. ${ }^{20}$

Many of the symptoms of FSD are commonly experienced in co-morbid conditions such as depressive mood disorder, pre-menstrual dysphoric disorder (PMDD) and peri-menopausal depressive disorder. Often the problem is more to do with insufficient sexual satisfaction and communication problems within interpersonal relationships than with true FSD. Alongside environmental factors, this can make the correct detection and diagnosis of these conditions difficult.

Specifically, certain disease states may increase vulnerability to FSD - for example diabetes mellitus. In one study $^{21}$ the most common symptom was a lack of libido (77\%). Diminished clitoral sensation (62.5\%), vaginal dryness $(37.5 \%)$, vaginal discomfort (41.6\%) and orgasmic dysfunction (49\%) were also very common. All of these related symptoms were significantly high when compared to controls. The existence of endocrinological disease, in particular sex steroids, prolactin and thyroid disease, is important particularly with HSDD. Other chronic medical conditions, including cardiovascular disease, anaemia and post-surgical menopause following bilateral ovarianectomy, will need specific enquiry.

\section{WHAT IS THE 'FEMALE SEXUAL RESPONSE'?}

The first accounts of female sexual response by Masters and Johnson $^{22}$ reported a linear progression from excitation and arousal, reaching a plateau-stage orgasm and resolution. Kaplan's model ${ }^{23}$ introduced the concept of desire bringing about arousal. More recently, Basson ${ }^{24}$ has proposed that the spontaneous sexual arousal experienced by women, where recognized, will in favourable circumstances bring about a desire for sexual activity and behaviour, especially when this is focused on enhancing intimacy and pleasurable outcome. The non-linear model of female sexual response incorporates an intimacy-based motivation model affecting sexual stimuli and co-influencing biological and psychological factors and satisfaction.

So should physicians in primary care treat or refer women with postmenopausal FSD? Sarrel ${ }^{25}$ has suggested that listening to the patient and clarifying her concerns are important for defining the nature of the problem, its severity and duration, and her motivation for treatment. A complete physical evaluation, including a pelvic examina- may provide important information for structuring a treatment plan to address the patient's concerns.

The role of questionnaires as an adjunctive tool in diagnosis and assessment of severity and bothersomeness of sexual problems in women is advocated by clinicians in the field. Some examples would include the female sexual function index, ${ }^{26}$ the Sexual Satisfaction Scale for Women $(\mathrm{SSS}-\mathrm{W})^{27}$ and the Scale for Quality of Sexual Function (QSF), which has been developed specifically as an outcome measure for therapies in men and women. ${ }^{28}$

\section{EXAMINATION AND INVESTIGATION}

There are few situations where a clinical examination would be contraindicated. Sexual aversion is often accompanied by autonomic symptoms with a feeling of fear and anguish. It may not be evident to either the patient or clinician until a routine gynaecological examination is attempted. An assessment of general constitution and cardiovascular status is essential. General inspection of the introital area and mons pubis is essential looking for localized pathology or evidence of local infection. The timing of any genital examination should be carefully considered and maybe carried out by the general practitioner during routine screening procedures or as part of a specific therapeutic process (for example using the method employed by the Institute of Psychosexual Medicine).

Assessment of androgen and oestrogen function, prolactin and thyroid levels are a baseline measure in cases of HSSD and arousal disorder. For anorgasmia, evidence of autonomic neuropathy may be detected by a full blood count and folate/B12 and testosterone levels. In all cases, blood glucose should be measured. The acidity of the vaginal cavity should be assessed (normal PH is less than 4.5). Assessment of vascular function using photoplesmography and vaginal thermal clearance are more specialized procedures available only in secondary services. ${ }^{29}$

\section{CLASSIFICATION AND DIAGNOSIS}

The diagnosis of sexual dysfunction in women is defined as a disorder of one or more of sexual desire, arousal, orgasm and/or a sexual pain (dyspareunia or vagnisimus). The condition must result in significant personal distress and have a negative impact on the woman's health and her quality of life. The co-existence of two or more of these conditions must be recognized in any assessment process and an evaluation of both the interpersonal relationship and the sexual health and well-being of the partner recorded. The diagnosis of one or more of these conditions is made primarily on the clinical history and by careful enquiry in each of the clinical areas. Many women will use euphemisms when discussing sexual issues until the patient and clinician are comfortable in using more specific and 
explicit language. Simple questions such as, 'Are you happy with your sexual life?' can be used in general consultations as an opening opportunity for patients to raise specific matters. With HSSD it is important to establish the biological motivational (emotional and affective matters and the need for intimacy) as well as the cognitive components (wishes and fears about sexual behaviour).

Mental health problems, especially depression and substance misuse, are common contributors to HSSD. Psychological experiences and life events - including work stresses, previous trauma and abuse - are important factors. In arousal disorder and anorgasmia, specific enquiry around vascular and neurological disease is essential. For example, diabetes mellitus can bring about both a sensory and autonomic neuropathy as well as small blood vessel disease. This can affect both the possibility of vasocongestion occurring and the woman's perception of this physical change. In the case of vaginismus, which is an involuntary contraction of the muscles around the entry point into the vagina, a history of difficulties in using tampons or having cervical inspections may be recalled. In cases of dyspareunia, the numerous gynaecology aetiologies must be considered for introital, vaginal and deep pelvic pain.

\section{TREATMENT OPTIONS}

Providing postmenopausal women with reassuring reading materials and focusing on their specific concerns about sexual dysfunction will help reduce anxiety. Alleviation of some menopause-related sexual function difficulties with prescription medications may be warranted, and referral to a specialist for further treatment and counselling may often be the best course of action for a primary care provider.

In many cases the opportunity for individual psychotherapeutic work and couple psychotherapy will be welcomed and useful in any package of care. Concurrent techniques of sex therapy, including sensate focus, are often beneficial. Information about sexual arousal, function and treatments is easily available now with various self-help sites on the internet and books, as well as instructional video tapes and DVDs.

In HSSD, where there are clinical symptoms suggestive of androgen deficiency (and which may not correlate with free testosterone levels), consideration of androgen therapy may be appropriate, especially in the post-menopausal state. Adequate oestrogenization is necessary, with localized therapies equally helpful for vaginal atrophy and dryness where systemic effects are not desired. Androgen replacement is typically given in the form of subcutaneous pellets, or more recently low doses of androgen gel, although this is offlicence. A new transdermal patch has recently been licensed in Europe $\mathrm{E}^{30}$ for women with symptoms following postsurgical menopause. Dehydroepiandrosterone (DHEA) tablets are another source of precursor androgens and are available over the counter, but base constituents of various preparations differ widely. Other medications that may be beneficial include bupropion, apomorphine (both offlicence) and, in post-menopausal women, tibolone.

In arousal disorder where there are problems with lubrication and concomitant dryness with pain, the use of lubricants is highly recommended. There are a number that mimic the nature of vaginal fluid, such as KY warming liquid - the first lubricant to be approved as a medical device by the FDA in the USA. Oestradiol therapy may be appropriate, usually topically. Off-licence medication may be useful to enhance congestion, including PGE5 inhibitors, apomorphine, ephedrine, phentolamine (all off-licence). Pelvic floor exercises and the use of aids and vibrators may be useful. The Eros-CTD has also been shown to be beneficial in increasing blood flow to the genital area.

In orgasmic disorder, medications that may help lower the threshold for orgasm include ephedrine, bupropion, yohimbine and bethanecol (all off-licence). Where there is specific antidepressant-induced anorgasmia, cyproheptadine or yohimbine may be helpful. The use of vibration and modified pelvic floor exercises can improve likelihood of orgasm. The role of cognitive behavioural therapy, particularly in promoting changes in attitudes to sexual thoughts, is particularly relevant in this condition, as is selfexploration with desensitization and guided sexual selfstimulation.

In dyspareunia where gynaecological conditions have been excluded or are managed concurrently, the role of topical local anaesthetics, oestrogen therapy and lubricants may be beneficial. Vaginsimus is usually treated using sexual therapy and vaginal trainers and dilators.

\section{CONCLUSIONS}

There is an evolving literature with regard to the anatomy, physiology and pharmacology of women's sexual function and dysfunction. The prevalence, diagnosis and treatment options continue to progress and physicians across specialities must become proficient and confident in attending to such problems, regardless of specialty.

Competing interests $\mathrm{KW}$ is a consultant to Proctor \& Gamble.

\section{REFERENCES}

1 Laumann E, Paik A, Rose R. Sexual Dysfunction in the United States: prevalence and predictors. JAMA 1999;281:537-44. Erratum: JAMA 1999;281:1174

2 Dunn KN, Croft PR, Hackett GI. Sexual problems: a study of the prevalence and need for health care in the general population. Fam Pract 1998;15:519-24 
3 Mercer $\mathrm{CH}$, Fenton KA, Johnson AM, et al. Sexual function problems and help seeking behaviour in Britain: national probability sample survey. BMJ 2003;327:426-7

4 Bancroft J, Loftus J, Long JS. Distress about sex: a national survey of women in heterosexual relationships. Arch Sex Behav 2003;32:193-208

5 Abdo CH, Oliveira WM Jr, Moreira ED Jr, Fittipaldi JA. Prevalence of sexual dysfunctions and correlated conditions in a sample of Brazilian women - results of the Brazilian Study on Sexual Behavior (BSSB). Int J Impot Res 2004;16:160-6

6 Cayan S, Akbay E, Bozlu M, Canpolat B, Acar D, Ulusoy E. The prevalence of female sexual dysfunction and potential risk factors that may impair sexual function in Turkish women. Urologia Int 2004;72: 52-7

7 Castelo-Branco C, Blumel JE, Araya H, et al. Prevalence of sexual dysfunction in a cohort of middle-aged women: influences of menopause and hormone replacement therapy. $J$ Obstet Gynaecol 2003;23:426-30

8 Safarinejad MR. Female sexual dysfunction in a population-based study in Iran: prevalence and associated risk factors. Int J Imp Res 2006;18: 382-95

9 Kadri N, McHichi Alami KH, McHakra Tahiri S. Sexual dysfunction in women: population based epidemiological study. Arch Women's Ment Health 2002;5:59-63

10 Moynihan R. The making of a disease: female sexual dysfunction. BMJ 2003;326:45-7

11 Hayes RD, Bennett CM, Fairley CK, Dennerstien L. What can prevalence studies tell us about female sexual difficulty and dysfunction? J Sex Med 2006;3:589-95

12 Mercer CH, Fenton KA, Copas AJ, et al. Who reports sexual function problems? STI 2005;81:394-9

13 Berman L, Berman J, Felder S, et al. Seeking help for sexual function complaints: what gynecologists need to know about the female patient's experience. Fertil Steril 2003;79:572-6

14 Nussbaum MRH, Gamble G, Skinner B, Heiman J. The high prevalence of sexual concerns among women seeking routine gynaecological care. J Fam Pract 2000;49:229-32

15 Barrett G, Pendry E, Peacock J, Victor C, Thakar R, Manyonda I. Women's sexual health after birth. BJOG 2000;107:186-95

16 Botros SM, Abramov Y, Miller JJR, et al. Effect of parity on sexual function: an identical twin study. Obstet Gynaecol 2006;107:765-70
17 Dennerstein L, Koochaki P, Barton I, Graziottin A. Hypoactive sexual desire disorder in menopausal women: a survey of Western European women. J Sex Med 2006;3:212-22

18 Wylie KR, Hallam Jones R, Daines B. An audit of an undergraduate medical school training programme in Human Sexuality. Medical Teacher 2003;25:291-5

19 Tsimtsiou Z, Hatzimouratidis K, Nakopoulou E, Kyrana E, Salpigidis G, Hatzichristou D. Predictors of physicians' involvement in addressing sexual health issues. J Sex Med 2006;3:583-8

20 Burd ID, Nevadunsky N, Bachmann G. Impact of physician gender on sexual history taking in a multispecialty practice. J Sex Med 2006;3, 194-200

21 Erol B, Tefekli A, Ozbey I, et al. Sexual dysfunction in Type II diabetic females: a comparative study. J Sex Marital Ther 2002;28(Suppl):55-62

22 Masters W, Johnson VE. Human Sexual Response. New York: Bantam Books, 1966

23 Kaplan HS. Disorders of Sexual Desire and Other New Concepts and Techniques in Sex Therapy. New York: Brunner/Hazel Publications: 1979

24 Basson R. Using a different model for female sexual response to address women's problematic low sexual desire. J Sex Marital Ther 2001;27:395-403

25 Sarrel PM. Sexual dysfunction: Treat or refer? Obstet Gynecol 2005, 106:834-9

26 Rosen R, Brown C, Heiman J, et al. The Female Sexual Function Index (FSFI): a multidimensional self-report instrument for the assessment of female sexual function. J Sex Marital Ther 2000;26:191-208

27 Meston C, Trapnell P. Development and validation of a five-factor sexual satisfaction and distress scale for women: the Sexual Satisfaction Scale for Women (SSS-W). J Sex Med 2005;2:66-81

28 Heinemann LA, Potthoff P, Heinemann K, Pauls A, Ahlers CJ, Saad F. Scale for Quality of Sexual Function (QSF) as an outcome measure for both genders? J Sex Med 2005;2:82-95

29 Nappi R, Salonia A, Traish AM, et al. Clinical biologic pathophysiologies of women's sexual dysfunction. J Sex Med 2005;2: 4-25

30 Davis SR, van der Mooren MJ, van Lunsen RH, et al. Efficacy and safety of a testosterone patch for the treatment of hypoactive sexual desire disorder in surgically menopausal women: a randomized, placebo-controlled trial. Menopause 2006;13:387-96 